\title{
SaCRALIZACIÓN Y DESACRALIZACIÓN DE LA LITERATURA EN LA OBRA DE ROBERTO BOLAÑo
}

\author{
Juan Sebastián Rojas Miranda* \\ Université Paris Ouest Nanterre La Défense \\ Laboratoire Littérature et poétique comparées
}

\section{Resumen}

Algunas obras de Roberto Bolaño se fundan en la mezcla entre literatura erudita y paraliteratura. Este encuentro entre aquellos dos géneros revela una manera particular de abordar la literatura menor. Consideramos las expresiones de lo menor como espacios de experimentación y comentario sobre la literatura. Gran conocedor de la paraliteratura, el autor se apropia de sus códigos para enseguida transgredirlos y agregarles elementos de comentario sobre la literatura, que encuentran en la paraliteratura un territorio de expansión perfectamente libre. Porque esta mezcla instaura un juego entre lo conocido, figurado por los códigos de la paraliteratura, y lo desconocido, que reside del lado del comentario sobre la literatura. Este escritor se ocupa así tanto de las fallas y ausencias de la historia literaria, de lo que esta no reconoce o ignora, como de lo que rechaza. Este trabajo está consagrado al estudio de este autor abierto a una nueva forma de literatura menor.

Palabras clave: Paraliteratura; literatura erudita; Roberto Bolaño; sagrado; chivo expiatorio.

Recibido: 15 de marzo de 2016

Aprobado: 11 de abril de 2016

*Doctorando Université Paris Ouest Nanterre La Défense.

Dirección electrónica : jsrojasmiranda@gmail.com 


\title{
Enshrinement and demystification of the literature in the work of Roberto Bolaño
}

\begin{abstract}
Some works of Roberto Bolaño are founded on the mixture between scholar literature and paraliterature. This reunion between those two genres reveal a particular way to approach the minor literature. We consider the expressions of the minor as spaces of experimentation and of commentary about literature. Well-known paraliterature experts, the author takes over its codes to immediately transgress them and add into them elements of commentary about the literature, that he found in the paraliterature a territory of expansion perfectly free. Because this mixture is a set up game between the well-known, figured by the codes of the paraliterature, and the unknown, that reside in the side of the commentary about the literature. Thus, this writer deal with gaps and absences of literary history, of which this one doesn't recognize or ignore, as much as it rejects. This work is dedicated to the study of this author opening to a new way of Minor Literature.
\end{abstract}

Keywords: Paraliterature; scholar literature; Roberto Bolaño; sacred; spacegoat.

\section{Cómo citar este artículo}

APA: Rojas Miranda, S. (2016). Sacralización y desacralización de la literatura en la obra de Roberto Bolaño. Poligramas, No. 42, pp. 19-32

MLA: Rojas Miranda, Sebastián. "Sacralización y desacralización de la literatura en la obra de Roberto Bolaño " Poligramas 42 (2016): 19-32 print..

Chicago: Rojas Miranda, Sebastián. 2016. Sacralización y desacralización de la literatura en la obra de Roberto Bolaño. Poligramas 42 (junio): pp. 19-32 
El siglo XX, heredero del concepto moderno de "literatura" elaborado en la época romántica, es aquel de la crítica literaria, pero también aquel en el que los escritores han escrito más sobre literatura. Sin embargo, esta última atraviesa una crisis profunda, al punto en que ciertos críticos postmodernos $^{1}$, en los años 70 , decretan su fin irremediable. Evidentemente, cualquier juicio y apreciación son solo relativos. No obstante, no nos ocuparemos en decir si conviene confirmar el fin de la literatura. Lo que no implica que persista la paradoja siguiente: es en el momento en que se considera la literatura en decadencia cuando se encuentra en el apogeo de sus comentarios. Por este hecho, esta literatura no puede ser cuestionada. Las reflexiones sobre la literatura no provienen solamente de autores de literatura francesa o inglesa, sino también de autores de otras literaturas como la chilena o la brasileña. No cabe duda de que en el siglo XX la novela, por su naturaleza misma, que permite la reagrupación de todos los géneros, como el del ensayo, ha sido considerablemente enriquecida por todas esas reflexiones. Pero según nuestro parecer, lo que es más interesante en esta situación paradoxal de la literatura es el hecho que jamás ha sido tan estrecha y profundamente ligada a las literaturas marginales, llamadas paraliteraturas ${ }^{2}$, como por ejemplo las novelas policíacas. ¿Esta relación es la prueba de

\footnotetext{
${ }^{1}$ Nuestra traducción de Six romanciers des années 1980-1990, Maryse Fauvel, Birmingham, Alabama, Summa Publications, 2007, p.8: «Los años 80 marcan no solamente la deconstrucción de la literatura, sino también el estallido del campo literario: no se trata más de la, sino de las literaturas en lengua francesa, en una época postindustrial en una cultura post-moderna, es decir según Lyotard, incrédula "de los metarelatos". El escritor no es más una figura que hablaría como un Camus o un Sartre en nombre de lo universal al pueblo francés. La literatura estalla en literaturas, y el público es atomizado."

${ }^{2}$ Nuestra traducción de Paralittératures, Daniel Fondanèche, Paris, Vuibert, 2005, p.692: "[Las paraliteraturas son] literaturas "bajas" término que recubre el Trivialliteratur alemán, de las literaturas populares, por consiguiente, buena para la canalla. Este género de argumento es todavía frecuentemente utilizado en los medios letrados bajo la forma de juicio de valor, cuando no de razón. La trama dramática es lineal, el vocabulario limitado, el estilo es estándar cuando no es familiar, los valores morales comunes. Ofrecen poco espacio a la reflexión (¿metafísica?). Se admite pese a todo que, a veces, algunas novelas de las paraliteraturas -fuera del género fantástico que tiene sus letras de nobleza- merecen un poco de atención, sin alcanzar sin embargo la perfección. Sin embargo, incluso las bellas letras no están exentas de debilidades: los lugares comunes, las longitudes, las digresiones sin interés, los personajes sin peso, los valores ordinarios, la banalidad de la trama dramática, incoherencias. Pero hay lo que es sacralizado por los misterios de la historia y lo que no es lo es todavía. ¿No es por eso que todo es bueno en las paraliteraturas? No, lejos, [...] ¿Habría entonces que elogiarlas? Elogiarlas, no, hacerlas conocer, sí, apostando por la inteligencia para distinguir entre lo que ha sido llevado a buen término de lo que no. Entre los dos, está la literatura que no es ni buena ni mala y que no tiene más valor que el que se le atribuye".
} 
la muerte de la literatura? Puesto que mezclándose a las paraliteraturas, ella pierde su grandeza... ¿O, al contrario, esta última experimenta una nueva juventud gracias a esta relación?

Es justamente esta mezcla particular, radical, podríamos decir, de la literatura erudita con las paraliteraturas que explica que su presente sea tan rico de nuevos lectores y escritores, que están a la búsqueda de estéticas no conformes con los cánones y las reglas del arte literario más en vigor borrando las distinciones que existen entre una literatura mayor y una menor. Esta nueva literatura erudita está impregnada de una especie de "carácter no oficial", indestructible, categórico, de modo que ningún dogmatismo literario, ninguna autoridad pueden armonizar con ella. Es decididamente hostil a todo juicio de valor negativo hacia las paraliteraturas.

Tomaremos como ejemplo la obra de Roberto Bolaño, novelista inspirado por la mezcla entre comentario sobre la literatura y paraliteratura. Nos interesaremos en cómo Roberto Bolaño como representante de la postmodernidad desacraliza la literatura, pero para proceder a su sacralización carnavalesca, lo que implica reconocer el estatus sagrado del escritor y que supone reactivar la violencia de lo sagrado a través la figura sacrificial del chivo expiatorio.

Estudiaremos entonces, en una primera instancia, la profanación de la literatura que se ejerce en la obra de Bolaño, y veremos en seguida que se expresa particularmente a través de la puesta en escena de un carnaval literario. Pero mostraremos, para terminar, que el doble juego de la profanación le permite realizar el retrato del escritor en tanto que chivo expiatorio, en el que mantiene el estatus de figura sagrada y sacrificial.

\section{Profanación de la literatura}

\section{Santuario profanado}

La literatura que va a cuestionar Bolaño es la literatura académica que ejerce una forma de santificación designando a los autores que merecen conformar el panteón de la literatura mundial. Va entonces a violentarla, a profanarla. 
El escritor chileno describe en Los detectives salvajes (1998) a personajes letrados que abandonan sus torres de marfil para convertirse en criminales. Pasan de un ambiente "sabio" a un ambiente "popular", a cielo abierto, donde la muerte no cesa de rondar. Esa transferencia es la ocasión para el escritor de confundir las fronteras entre aquellos dos universos, y por lo tanto de la literatura y de la paraliteratura, la academia y la calle. Pone en escena a eruditos detectives, obsesionados por la musa de la literatura, que llegan hasta autoanalizarse y se califican ellos mismos de personajes de novela policíaca. Se siente obligado de revisar sus concepciones sobre la literatura, en particular sobre lo que, como la novela policíaca, fue rechazado al margen de su universo erudito.

En la obra de Bolaño la literatura es un objeto de búsqueda para los personajes que atraviesan el mundo. El encuentro entre literatura erudita y paraliteratura se realiza a través del juego. Un banal juego de enigmas se transforma por ejemplo en el objeto principal de la intriga. Como un Jano, aquel principio lúdico enarbola dos rostros muy diferentes que se complementan sin embargo: el uno exalta la riqueza de la paraliteratura, del "paganismo literario"; el otro de la historia literaria, todo lo que es sacralizado en literatura, puesto que el juego es la característica primera del movimiento literario que buscan los poetas detectives.

El mundo infinito de las formas y manifestaciones de la mezcla entre literatura y paraliteratura se opone a la cultura oficial, al academismo, defendido a veces con fanatismo y que desde hace apenas unos años comienza a estudiar las paraliteraturas. En toda su diversidad son representadas estas formas y manifestaciones: batallas épicas en torno a una poetisa imposible de encontrar en la ciudad y cuyo testimonio puede cambiar la historia de la literatura; técnicas narrativas propias de los folletines que otorgan una dinámica particular a la construcción de un discurso sobre la literatura, sin caer en la vulgarización; detectives y criminales perdidos en bibliotecas míticas o intelectuales célebres que dialogan con pillos en parques peligrosos, como Octavio Paz en la capital de México; literatura paródica, basta y variada que se burla de los discursos apocalípticos sobre ella misma... Todas estas formas poseen una unidad de estilo y constituyen las partes y parcelas de una nueva literatura, inspirada particularmente en la mezcla de erudición y 
de cultura popular de obras como aquellas de François Rabelais o de Miguel de Cervantes.

La estructura sinusoidal de los relatos en las paraliteraturas, como ha sido identificada por Umberto Eco en su ensayo De Superman al Super Hombre (1976), es primeramente la principal característica de la nueva literatura erudita. Esta disposición se encuentra en el origen de una estética que valoriza el aspecto lúdico de las paraliteraturas.

Este aspecto lúdico permite poner en duda la construcción de todo comentario pretendidamente científico sobre la literatura.

Los detectives salvajes de Roberto Bolaño puede ser leída como un balance de la literatura latinoamericana después del boom de los años 60 y 70 (boom que tiene lugar en los tiempos de la crisis del fin de la literatura). ¿Cómo hacer entrar la historia literaria en el universo de la ficción cuando compete más bien a los "científicos"? Con una buena dosis de novelesca. La primera palabra del título de la novela es muy significativo, "Los detectives". La figura del detective se encuentra en desde la literatura de masa (como en la literatura policial) hasta en las ficciones eruditas convertidas en best sellers como El nombre de la rosa de Umberto Eco (1980). No hay necesidad de describir a un detective, ya está inscrito en el imaginario colectivo.

Los héroes urbanos de Roberto Bolaño desmontan la figura positivista del detective propuesta por la paraliteratura. En vez de la búsqueda modernista del sentido en ciudades caóticas como México, el autor evita de manera lúdica toda posibilidad de sentido. Los detectives de su novela asumen su búsqueda como un juego. La última palabra de la novela es uno: un enigma que los personajes no logran resolver.

En contra de esta búsqueda de sentido, hay una arquitectura del azar. El azar objetivo de André Breton, aquella creencia en el encuentro entre el deseo humano y las fuerzas misteriosas que favorecen su realización es parodiado. Uno de los héroes de Bolaño lo aplica para encontrar números de calles que le van a permitir ganarse la lotería.

La empresa de desmontaje de ciertos elementos de las novelas policíacas a través del juego pasa también por diferentes formas y géneros del vocabulario familiar y grosero urbano (injurias, blasfemias, palabrotas) y una gran variedad de pasajes cómicos. Todas esas 


\section{Poligramas 42 - junio de 2016}

expresiones organizadas con el modo cómico y lúdico son repartidas en universos pluri-vocálicos, multi-geográficos y multi-temporales.

En el estado de las confusiones de las voces, del espacio y del tiempo, el aspecto conflictual de la percepción del mundo, de la vida humana y de la literatura es de una gran envergadura. Encontramos, en ese caos, paralelamente a las concepciones reaccionarias de la literatura de parte de ciertos eruditos y movimientos literarios, como los surrealistas parodiados por Bolaño, expresiones burlonas, que ridiculizan y blasfeman toda institución o grupo de personas que se pretenden serias; para oponerse a los discursos serios, están los discursos cómicos e injuriosos; para oponerse a los héroes que encarnan figuras eruditas célebres, están sus versiones paródicas.

Los elementos paródicos presentes en el desarrollo de las intrigas de Los detectives salvajes son el triunfo de una especie de emancipación provisoria contra la verdad dominante y del orden existente, de abolición provisoria de todas las relaciones jerárquicas, privilegios y reglas. Es la naturaleza auténtica de la literatura, aquella del porvenir, de las alternancias y de los renacimientos. Esta se opone a toda perpetración, a todo acabado y término. Siempre está en fuga; mira hacia un futuro inacabado. La literatura está marcada, particularmente, por la lógica original de las cosas "al revés". Por las formas más diversas de las parodias y de los abatimientos. Por la profanación.

\section{Efecto paradógico de la profanación}

Ahora, el efecto paradógico de la profanación en la obra de Bolaño es que, pese a su intención, acaba al servicio de la valorización del sistema dominante.

La profanación no saca la literatura del orden existente, no crea una alternativa. Al contrario, no hace más que consagrar, perpetuar el orden en vigor, lo fortifica: salva las instituciones en crisis desde la postmodernidad. El nexo con las paraliteraturas pasa a ser puramente formal, cada intriga de las novelas está al servicio de la valorización del sistema dominante: aquel de la literatura erudita.

Una característica específica de la obra de Roberto Bolaño es que sus intrigas principales están ligadas a una reflexión sobre la poesía, y 
que está concebida bajo su forma más ideal es extranjera a la ciudad. En efecto, la poetisa tan buscada por los detectives salvajes es encontrada en el espacio rural, en el desierto de Sonora. En Los detectives salvajes, encontramos constantemente en la base de la novela una concepción determinada y concreta de la literatura, en la cual la poesía ocupa el primer lugar, mientras que el último lugar está ocupado por formas prosaicas propias a las paraliteraturas, como la biografía.

Es justamente a partir de aquel subgénero ${ }^{3}$ que la intriga de la novela de Bolaño se desarrolla. Los detectives de la novela son una especie de biógrafos en busca de una poetisa excepcional. La resolución de la intriga consiste en su descubrimiento, que representa el destronamiento del poeta Octavio Paz en el reino de la literatura latinoamericana. Bajan un rey para poner otro. La intriga es como un viaje vertical de la paraliteratura a la cumbre más elevada de la literatura: la poesía. Un viaje del espacio urbano al espacio rural, de diferentes ciudades del mundo al África salvaje, donde uno de los héroes principales parece reproducir el gesto del poeta Arthur Rimbaud diciendo adiós a la literatura.

El rol de la profanación es entonces confirmar lo sagrado. La estrategia de Bolaño consiste en confirmar la existencia de lo que profana. Reafirmar lo sagrado de la literatura por la violencia de la blasfemia. Bolaño crea un círculo vicioso para mantener la sacralización. Un círculo que tiene la apariencia de una fiesta de carnaval. Es lo que veremos en nuestra segunda parte.

\footnotetext{
${ }^{3}$ Nuestra traducción de Paralittératures, p.20: "Me parece que se podrían distinguir algunas categorías basándose en la idea de que existe una suerte de tronco común, un zócalo, reúne diversas paraliteraturas. Estas diferentes bases permiten, a mi parecer, orientar la reflexión dándole un punto de partida que no se basa solamente en una fecha, un estilo, una temática, sino en un cimiento más amplio. Cierto, este punto de vista es sin duda discutible, como todos los enfoques de hecho, pero tengo el sentimiento de que si no se desea caer en una visión demasiado especializada (el riesgo del puntillismo no está lejos) de una de las paraliteraturas, hay que tener una visión lo más distanciada posible. Estos zócalos podrían presentarse así: EL zócalo especulativo con: la novela policíaca (y todas sus subcategorías), la novela de ciencia ficción (con todas sus subdivisiones), la novela fantástica (bajo todas sus formas), la utopía y la distopía; el zócalo de la aventura con la novela de espionaje y la novela de western; el zócalo psicológico con la novela sentimental y su corrupción, la novela rosa; entre las dos, la novela erótica que tiene su propia forma pervertida, la novela "X"; el zócalo icónico con la historieta y la foto-novela (incluyendo también la "cine novela"); el zócalo documentario con la novela histórica, la ucronía y la novela rural."
} 


\section{Carnaval literario}

\section{Cómo proceder con una perversión}

En esta fiesta, los aspectos serios y cómicos de la literatura, del mundo y el hombre son, de acuerdo a toda apariencia, igualmente valorizados, igualmente admitidos. Y los discursos místicos de la literatura también.

¿Cuáles son las características específicas de los discursos místicos en la novela y, ante todo, cuál es la naturaleza, es decir, cuál es su modus operandi?

No se trata naturalmente de discursos a tomar en serio. El principio cómico que pervierte toda afirmación proclamándose única sobre la literatura los libera totalmente de todo dogmatismo, están en pocas palabras enteramente desprovistos de algún carácter mágico o encantador. Mejor todavía, algunos pasajes de Los detectives salvajes son una verdadera parodia del misticismo, como es el caso cuando los poetas son presentados como santos o diablos, para en seguida ser tratados como pobres diablos.

La novela de Bolaño pervierte la figura del poeta-profeta refiriéndose a la mitología bíblica, principalmente la del Nuevo Testamento. Bolaño hace un paralelo entre el desierto de Sonora y aquel donde Jesús se encuentra con el diablo. Jesucristo es un chivo expiatorio que inspira al autor para desacralizar la mística. A partir de esta figura crea poetas malditos, antihéroes.

\section{La puesta en escena del antihéroe carnavalesco}

En otras novelas de Bolaño como Estrella distante (2002), la figura del antihéroe protagonista representa un hibrido entre Jesús, el "pastor" y el anticristo. Sería interesante analizar el tema de la maldición, presente a lo largo de Los detectives salvajes. La maldición es un estado de desgracia ineluctable, susceptible de ser compartido con alguien más, o incluso con una institución. En la novela de Bolaño, un editor impactado por la mirada de zombi demoníaco de Arturo Belano duda en publicar una antología de poemas del movimiento de este. Finalmente decide hacerlo y algunos meses más tarde su casa editorial cae en bancarrota, como si estuviera maldita. La maldición en la obra 
de Bolaño tiene como propósito anunciar el carnaval último. Aquel que anuncia un nacimiento. Muy seguido, sus antihéroes tienen como función preparar el terreno para abrir la brecha a una nueva poesía, de la misma manera que lo hicieron ciertos escritores románticos como Victor Hugo, Chateaubriand o como el poeta no romántico Mallarmé.

En Los detectives salvajes, la ciudad aparece a menudo como un espacio extraño donde tienen lugar los duelos entre poetas sacralizados pero malditos y vagabundos. El "chronotope" del relato de Roberto Bolaño, es decir, la solidaridad entre el lugar y el momento, encuentra a menudo su lugar en las organizaciones de la vida familiar, social e incluso nacional. Entre cada peripecia de los personajes, estos últimos deben tener encuentros que no son reglamentados: el tiempo y el lugar no están establecidos según el rango del sujeto encontrado (los vagabundos criminales conspiran en las casas de sus familias; los poetas sacralizados se pasean por las calles más peligrosas; y la sacralización de la literatura no tiene lugar en las instituciones académicas, sino en cavernas a veces poseídas por el demonio. Se trata entonces de un intercambio particular entre lo sagrado y lo profano.

La práctica de una literatura de pésimo género (vulgar y baja literatura)

Es preciso decir que un nuevo tipo de intercambio contrae nuevas formas de lenguaje. Bolaño se inscribe en la práctica de una literatura de pésimo género: en esta se emplean expresiones de la calle o de los comerciales televisivos; se utilizan latinismos para crear un ambiente "retro", propio de la paraliteratura. No hay ninguna necesidad de crear un lenguaje pulcro, las palabras y expresiones impertinentes irrumpen en los relatos.

Lo que nos interesa especialmente es el aspecto ambivalente de la grosería. Pese a que rebajan y mortifican, valorizan al mismo tiempo ciertos aspectos de la literatura. Gracias a esta ambivalencia, la grosería y los insultos contribuyen a crear una atmosfera de libertad y de tonalidad cómica. Encontramos a menudo en Los detectives salvajes un personaje de novela de aventuras y otro de novela policíaca que se insultan para defender sus ideas. Y vagabundos que sacralizan la literatura como los peregrinos su religión. 
Roberto Bolaño representa a intelectuales latinoamericanos que llevan una vida precaria en los bajos fondos de las ciudades, con los dealers y los sicarios, y que tienen ellos mismos también rasgos criminales. La desaparición de esta frágil frontera social pertenece a la estética del rebajamiento, característica del realismo grotesco, según Mikhaïl Bakhtine en la obra de François Rabelais (1965):

"El rebajamiento, es decir la transferencia de todo lo que es elevado, espiritual, ideal y abstracto al plano material y corporal, aquel de la tierra y del cuerpo en su insoluble unidad."

De este modo con Bolaño la risa reencuentra una forma de lo sagrado poniendo a su vez la mística en el corazón de la literatura. ¿Qué es la mística? Es también una forma de violencia. como la practicaban los místicos como San Juan de la Cruz: "Nada, nada, nada y aún en la montaña nada". Aquel místico no llegó a negar la Trinidad, como los místicos negativos. Para estos, Dios es la nada absoluta que viene de "néans", cuya etimología latina quiere decir "no persona". Lo que buscan los místicos negativos es la nada absoluta. En la obra de Bolaño, el abandono a la literatura es como el abandono a Dios. El último sacrilegio de los poetas malditos de Bolaño es ir en busca de la literatura imposible, como el dios de los místicos. Todo arrebato místico, todo éxtasis es violencia, como lo es todo goce. El retrato de los poetas malditos es lo que veremos en esta tercera y última parte.

\section{Retrato del escritor como chivo expiatorio}

\section{Figura del poeta maldito}

Bajo un modo paródico aparece la violencia de la mística. Otra forma de profanación del dogma y según los místicos negativos, la más auténtica de lo sagrado. Su propósito es destruir las falsas iglesias, los falsos templos. Detrás del aspecto novelesco del antihéroe letrado de Bolaño se encuentra la representación del vanguardista que debe sacrificarse para que la literatura exista. La vanguardia es un término militar que recuerda a Rimbaud. Según él, los escritores deben ir delante

\footnotetext{
${ }^{4}$ La traducción es nuestra
} 
de la Historia. Una reflexión que la postmodernidad critica. Lyotard la criticó en La condición postmoderna. Sin embargo, en la obra de Bolaño, autor de una antología poética con el título "rimbaldiano" Reinventar el amor (1976), prevalece aquella idea de Rimbaud en la que la figura sacrificial del artista tiene un rol crucial.

Bolaño se inscribe en la tradición "baudelairiana" de los poetas malditos. Entre los fenómenos de sacralización, se haya el poeta maldito que el poeta Antonin Artaud llama el "suicidado de la sociedad", el "chivo expiatorio". A través de este mito romántico, el autor chileno reactiva la figura antigua sacrificial. En efecto, esta búsqueda de una literatura nueva pasa por formas y figuras antiguas.

El carnaval de los poetas malditos se parece a las peregrinaciones antiguas, como aquella narrada en la primera novela carnavalesca: $E l$ asno de oro, de Apuleo. En este última, un hombre es transformado por una maldición en asno y es conducido por una diosa en una peregrinación con el fin de recuperar su forma humana. Bolaño, autor de una antología de poemas con el título como un verso del vanguardista Rimbaud Reinventar el amor, pone sus detectives salvajes a peregrinar por el mundo en nombre de un nuevo amor, una literatura nueva.

\section{Reactivación de las formas y figuras antiguas}

En Los detectives salvajes, Juan García Madero, el único detective salvaje de la novela que conoce un final feliz, desiste de la empresa vanguardista y dedica su vida al amor y a la familia. Esto puede hacer pensar en la noción del destino presentado en el Mito de Aquiles, el héroe de La Ilíada, que, antes de partir a Troya, debe decidir entre tener una vida corta, intensa y gloriosa o una vida corta y pacífica. Entre el personal novelesco que representa a los hombres de letras, únicamente Juan García Madero escoge la segunda opción e, irónicamente, no figura en el libro de historia del movimiento visceral realista, pese a formar parte de él. No figura en la historia literaria y por consecuencia salva su vida.

Juan Garcia Madero decide no participar en ese carnaval literario lleno de misticismo violento. De hecho, el carnaval es una transposición aparentemente profana, lúdica de lo sacrificial, teorizado por René 
Girard. El carnaval se termina con el sacrificio del chivo expiatorio. No hay nada más serio que el carnaval. Es una violencia hecha al orden establecido. Reactiva lo sagrado a través de personajes de carnaval, y así, pone en duda las reglas sociales y religiosas. Pero eso no quita que Bolaño preserve la figura sagrada y sacrificial del escritor. De ahí el retrato del artista en tanto que chivo expiatorio.

La palabra "detectives salvajes" en la novela de Bolaño puede hacer referencia a personas a la vez especialistas y salvajes, a antihéroes fuera de la ley y particularmente a distancia de los paradigmas literarios. De hecho, los detectives fundan un movimiento, el realismo visceral, que tiene por principal característica refutar la historia literaria oficial y su figura de proa, Octavio Paz. Como buenos Robin Hood de la literatura, proyectan secuestrarlo. La novela puede ser vista como un ritual de sacrificio de los antihéroes poéticos. Este aspecto de la literatura, que como un dios mexicano que reclama cuerpos a sus adoradores a cambio de sus vidas, domina la novela de Roberto Bolaño, cuya narración acaba al mismo tiempo que los poetas vagabundos desaparecen, lejos de la ciudad, algunos en el violento desierto de Sonora donde tienen lugar las masacres de su novela póstuma 2666 (2004). Y en la cual el protagonista escritor, gigante como el Gargantúa de la novela carnavelesca epónima de Rabelais, da punto final a su larga andanza.

Todos los recursos paródicos, todos los rebajamientos en la obra de Roberto Bolaño son herederos del carácter mítico y sagrado de la literatura.

Podemos afirmar para concluir que, a punta de deconstrucción profana y carnavalesca, se reactiva la dimensión sagrada de la literatura y sacrificial del escritor, lo más cerca de la violencia colectiva en su relación con la sociedad. El poeta maldito en la obra de Bolaño existe para revelar la violencia fundamental de la sociedad. Como dice Artaud, él es un chivo expiatorio que lleva a cuestas todas las violencias de la sociedad para liberarla. 


\section{Referencias bibliográficas}

Artaud, A. (2004). Euvres. París: Gallimard.

Bakhtine, M. (1975). Esthétique et théorie du roman. (trad. Olivier, D.). París:

Gallimard,

. (1965). L'Euvre de François Rabelais et la culture populaire au Moyen

Âge et sous la Renaissance. (trad. Robel, A.). París : Gallimard.

Bolaño, R. (1998). Los detectives salvajes. Barcelona: Anagrama.

. (2009). Los perros romańticos: poemas 1980-1998. Barcelona:

Acantilado.

. (2009). Una novelita lumpen. Barcelona: Anagrama.

. (2004). 2666. Barcelona: Anagrama.

Cervantes, M. (2010). El ingenioso hidalgo Don Quijote de la Mancha. Barcelona: Plutón.

Eco, U. (1976). Il superuomo di massa. Milano: Bompiani. . (2000). Il nome della rosa. Milano: Bompiani.

Fauvel, M. (2007). Six romanciers des années 1980-1990. Alabama: Summa Publications.

Fondaneche, D. (2005) Paralittératures. París: Vuibert.

Girard, R. (2009). Le Bouc émissaire. París: Grasset.

Lyotard, J-F. (1985). La Condition post-moderne. Rapports sur le savoir.

París: Minuit.

Rabelais, F. (1955). Euvres complètes. (ed. Scheler, L.). París: Gallimard. 